\author{
Revista Venezolana de Gerencia (RVG) \\ Año 10. № 31, 2005, 355-356 \\ Universidad del Zulia (LUZ) • ISSN 1315-9984
}

\title{
EDITORIAL \\ LAS ORGANIZACIONES DE LA ECONOMÍA SOCIAL EN LA MIRA DE LA RVG
}

Varios son los temas importantes para este editorial, uno de ellos es el reconocimiento que el Ministerio de Ciencia y Tecnología (MCT), la Fundación para la Ciencia y la Tecnología del Estado Zulia (FUNDACITE-ZULIA) y la Universidad del Zulia (LUZ), hicieron el pasado 3 de junio a los investigadores acreditados en el Programa de Promoción al Investigador (PPI), ya que LUZ fue la institución con mayor número de investigadores acreditados en el referido programa. Dejamos constancia de este merecido homenaje con el discurso del Dr. Álvaro Márquez en ese acto, el cual hemos incorporado en este número de la RVG.

Otro tema importante que hemos dejado de lado, es el trabajo de diez años consecutivos de la RVG; dejamos constancia de este aniversario en la portada de la revista, pero además brevemente es necesario señalar que este esfuerzo al igual que el de las otras revistas de LUZ, ha contribuido al avance de la institución en el crecimiento de su comunidad científica; no se trata simplemente de que existen alternativas para la publicación, sino que éstas son de calidad, ya hemos señalado en un editorial anterior, la calificación que recibieron las revistas en la evaluación de méritos realizada por el Fondo Nacional de Ciencia, Tecnología e Innovación (FONACIT). La RVG, obtuvo la mayor puntuación de (LUZ) y la mayor puntuación en las áreas de ciencias sociales y humanas del país.

El tercer asunto, en el cual nos vamos a detener, es el que colocamos EN LA MIRA en este número: LAS ORGANIZACIONES DE LA ECONOMÍA SOCIAL, su importancia para Venezuela y América Latina hoy más que nunca nos lleva a optar por dedicarle más espacio que a los otros.

La economía social es un tema de viejo interés académico en América Latina, a pesar de la escasa importancia que ha tenido en la práctica en relación con la economía tradicional. Este interés científico tiene que ver con la necesidad de explicación de una realidad compleja, con profundas dificultades para crecer y desarrollarse en los términos planteados como economía alternativa; estas dificultades han tenido lugar en un contexto de esfuerzos y demandas que hacen los sectores sociales más desfavorecidos, en torno a la creación de organizaciones alternativas a las empresas capitalistas, como estrategias laborales y en general de mejoramiento de las condiciones de vida.

Son numerosos los problemas existentes en el plano del conocimiento respecto a esa realidad que estamos Ilamando economía social, uno de ellos es su conceptualización, la cual en definitiva tiene que ver con la concepción del fenómeno. Otros conceptos, nociones o términos, son utilizados para dar cuenta de una economía diferente a la capitalista, que no tiene como ésta fines de máxima rentabilidad del capital. Entre esos conceptos se encuentran, además de economía social: economía popular, economía solidaria, tercer sector productivo, economía de acompañamiento, economía a escala humana y economía mutual. Se trata de conceptos que incorporan en cada caso características distintivas de los otros, pero esencialmente intentan definir una economía alternativa a la capitalista. 
Identificar los rasgos fundamentales de la economía social es otro problema científico, en torno al cual existe poco consenso, nuestra tesis es que la definición, la cual implica descubrir las características esenciales, requiere estudiar los procesos de gestión de las organizaciones que la conforman: microempresas, cooperativas, unidades de producción indígena y otras organizaciones productivas con propósitos formales distintos de la rentabilidad del capital. Sólo penetrando en estos procesos de gestión (que constituyen el motor de las organizaciones) y en sus efectos políticos, económicos y sociales, en los trabajadores y en la sociedad, es posible avanzar en la definición de la economía social. Conocer la gestión de las organizaciones que formalmente se definen como alternativas a las empresas capitalistas, nos permite conocer sus propósitos reales, así como su aporte a la construcción de una economía alternativa, más allá de las definiciones formales y de los buenos deseos de quienes aspiran a construir una economía donde se remunere el trabajo por encima del capital.

Estamos en tiempos en los cuales es urgente dar respuesta a este problema científico, la economía social es hoy más que nunca la esperanza de numerosos latinoamericanos que luchan por un mejor nivel de vida, algunos países dedican cuantiosos recursos a organizaciones productivas alternativas a la capitalista, es el caso de Venezuela, donde según cifras de la Superintendencia Nacional de Cooperativas, se pasó anualmente entre 1998 y 2004 de 762 cooperativas a 820, 1006, 1927, 4078, 12145, 54242 respectivamente y 83769 hasta agosto de 2005, es decir un crecimiento del $10993 \%$ en relación a 1998, esto sin tener en cuenta otras formas productivas consideradas como alternativas a la capitalista. Estudiar la gestión de estas cooperativas es lo que nos puede permitir conocer el verdadero carácter de este esfuerzo formal en torno a la construcción de una economía social.

En este número, correspondiente al año en el cual la RVG cumple diez años de edición consecutiva incorporamos EN LA MIRA cuatro trabajos sobre organizaciones de la economía social. Alberto Bialakowsky de la Universidad de Buenos Aires y su equipo de investigación de las cooperativas que han surgido de empresas recuperadas en Argentina, nos entrega su trabajo titulado: Gerencia de Empresas recuperadas por los trabajadores en Argentina; Nila Fuenmayor de LUZ y Lucrecia Acurero de la Universidad Bolivariana de Venezuela (UBV) nos presentan resultados de la investigación titulada: Política de fomento a la economía social en la gobernación del Estado Mérida; de la UNAM-México, la profesora Tania González analiza Problemas en la definición de Microempresas y de la Universidad de Carabobo en Venezuela, Karelys Osta y Hermelinda Mendoza hacen una reflexión sobre la actividad cooperativa en Venezuela.

En la sección trimestre incorporamos el trabajo de Egon Montecinos de la Universidad de Los Lagos, titulado: Antecedentes sobre la relación histórica centralismo y descentralización en Chile; de Omar Guerrero de la UNAM-México publicamos el artículo titulado: La gerencia pública en la sociedad post-industrial; Norcka Fernández, Dionnys Peña y Nelly Primera, investigadores de LUZ, nos entregan un trabajo sobre Administración de políticas de información al ciudadano: Caso Alcaldía de Maracaibo; y también de LUZ Yhajaira Bracho, María C. González y Anaís Álvarez, presentan los resultados de su investigación sobre Comportamiento de la rentabilidad de la banca venezolana.

Finalmente, como hemos dicho, incorporamos el texto del discurso del Profesor Álvaro Márquez, titulado: Hacia un ideal práctico para sentir y vivir lo que es la Universidad.

Agradecemos una vez más a los colaboradores de la RVG su confianza en nuestra revista.

\author{
Haydée Ochoa Henríquez*
}

* Directora de la Revista Venezolana de Gerencia. Investigadora de la Universidad del Zulia, acreditada en el Programa de Promoción al Investigador (PPI). 